\title{
Sense-Giving Systems for Crisis Situations in Extreme Environments
}

\author{
Abbas Strømmen-Bakhtiar and Eystein Mathisen \\ Centre for Enterprise Architecture and Information Systems, \\ Bodø Graduate School of Business, University of Nordland, \\ Bodø, Norway
}

\section{Abbas.Strommen-Bakhtiar@uin.no, Eystein.Mathisen@uin.no}

\begin{abstract}
The latest agreements between Norway and Russia with regard to their delimitations of their borders and the discovery of large oil reserves in the high north area (Arctic) have opened the way for oil companies to push ever deeper in this area searching for oil. Exploration activities are already underway and production platform are soon to follow.

Arctic has one of the most pristine, yet inhospitable environments on the planet. Any minor event in this environment can easily become a major disaster not only for the people and companies involved but also for the local environment and its ecosystem.

This paper considers the problem of decision making in response to extreme events taking place in extreme environments (context). Various decision making models are examined reaching the conclusion that unstructured decision making model is the most suitable mode of decision making in these circumstances. In addition the role of Decision Support Systems (DSS) as an adjunct or a sense giving system to the decision maker is considered.
\end{abstract}

Keywords: Decision Support System (DSS), Extreme Event, Extreme Context, Situation Awareness (SA), Sense Making, Sense Giving, Information, Decision Making, Rational Models, Naturalistic Models.

\section{Introduction}

It is widely accepted that the non-renewable energy resources such as oil and gas will eventually run-out. According to British Petroleum (British Petroleum, 2010) with the current consumption rate and oil and gas reserves, the world will run out of both within the next $40-60$ years. The problem is compounded by the fact that a few large countries such as China, India, Brazil and others are growing rapidly, increasing their rate of consumption. In 2010 for example, China's oil consumption grew by $12.8 \%$, while "according to International Energy Agency (IEA), the

Material published as part of this publication, either on-line or in print, is copyrighted by the Informing Science Institute. Permission to make digital or paper copy of part or all of these works for personal or classroom use is granted without fee provided that the copies are not made or distributed for profit or commercial advantage AND that copies 1) bear this notice in full and 2) give the full citation on the first page. It is permissible to abstract these works so long as credit is given. To copy in all other cases or to republish or to post on a server or to redistribute to lists requires specific permission and payment of a fee. Contact Publisher@InformingScience.org to request redistribution permission. world's oil supply grew by just 1.3 million barrels per day. That is just $1.53 \%$ increase vs. 2009" "“China oil demand is 'astonishing,," 2010).

This rapid increase in consumption is taking place exactly when the oil production is on the decline (Bentley, 2002; Kerr, 2011; Skrebowski, 2003) and new reserves are hard to come-by (Aftabuzzaman \& Mazloumi, 2011; 
Aleklett \& Campbell, 2003a). It is therefore not surprising to see that major oil companies are expanding their exploration / production activities to ever more dangerous and hostile environments, such as offshore at ever increasing depths and the Arctic region or both.

The Arctic region, in particular, is highly attractive since it is supposed to contain ca $13 \%$ of the world's undiscovered oil and 30\% of its undiscovered gas (Donald L. Gautier, Bird, et al., 2009). According to the 2008 survey by United States Geological Survey (USGS), 84\% of these reserves are to be found offshore.(D. Gautier, 2011)
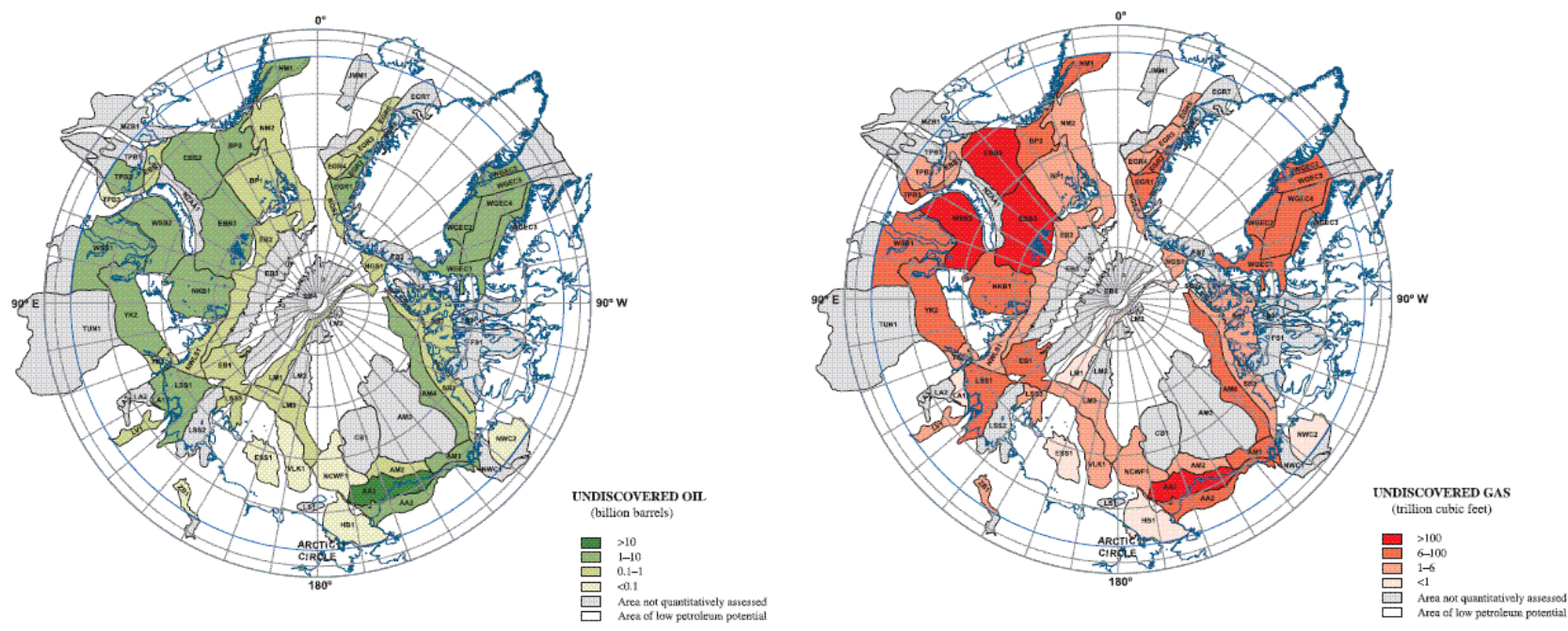

Figure 1. Assessment units (AUs) in the Circum-Arctic Resource Appraisal (CARA) colourcoded by assessed probability of the presence of at least one undiscovered oil and/or gas field with recoverable resources greater than 50 million barrels of oil equivalent. Source: (D. L. Gautier, Bird, et al., 2009)

\section{The Arctic Region and its Environment}

The rush to Arctic both onshore and offshore present the oil companies, supply vessel companies and others who are going to operate in the region with particular problems that are unique to the region.

Arctic, unlike Antarctic, is not a continent. The Arctic area is a region that includes Arctic Ocean and parts of Norway, Sweden, Finland, Iceland, Greenland, Russia, Canada and the United States. Arctic region, with average winter temperatures of close to $-40^{\circ} \mathrm{C}$, and with long and totally dark winter months (ca 6 months/year) is an inhospitable area to operate in.

Arctic Ocean, which lies at the centre of the arctic region and covers a 14 million $\mathrm{km}$ area, is not easy to traverse either. Arctic Ocean, with an average depth of $1050 \mathrm{~m}$, is one of the shallowest and coldest oceans in the world. During the winter months much of this ocean is covered by almost 3 meters of ice and during the summer months, the total icepack shrinks by nearly $50 \%$, allowing some degree of navigation by ships.(Pidwirny, 2006)

Operating in such a hostile environment can be specially challenging for supply vessels, their equipments and crew; magnifying complex problems that must be analyzed and solved when planning and executing operations in the region. According to Mejlænder-Larsen (MejlænderLarsen, 2011) of 'Det Norske Veritas AS', Liv Nilsen (Nielsen, 2011) of 'ENI Norge AS.', and Øystein Mikelborg (Mikelborg, 2011) of 'Norwegian Polar Institute' the main challenges in the arctic are: 


\section{Sense-Giving Systems}

- Cold and harsh climate: crew

- Extreme seasonal variations: equipment \& crew

- Low temperature: hull and equipment

- Snow, slush, fog and icing: operations

- Ice: hull and structure

- Sea Ice: navigation, ice breaking, etc

- Lack of precise and accurate (sea maps): navigation

- Remote location: operation

- Darkness: crew, operations

- Icebergs: ships

- Low traffic density: lack of vessels of opportunity if an accident occurs

These factors contribute to the creation of what one may call an extreme environment in which minor accidents or incidents can easily turn into major events or crisis. Making decisions in a crisis situation is never easy and it is made more difficult when that crisis is taking place in an extremely inhospitable environment, where a wrong decision can result in loss of life.

This paper is organized into 8 sections. Section one is the introduction. Section two discusses the meaning of the term crisis and crisis in extreme environments or context. Section three examines the first step in decision making, namely sense making or situational awareness, followed by section four which discusses the process of sense giving, i.e. Informing others about the situation. Section five reviews the existing decision making models (structured vs. Unstructured/semistructured). The final section presents the conclusion.

\section{Crisis in Extreme Context}

There are many definitions of crisis, all of which point out the potential for a negative outcome of the future events based on the decisions taken at a particular stage in a sequence of events. For example, James (2008, p. 3) after considering 6 definitions proposed by other researchers defines crisis in a very personal way, as "a state of disorganization in which people face frustration of important life goals or profound disruption of their life cycles and methods of coping with stressors. The term crisis usually refers to a person's feelings of fear, shock, and distress about the disruption, not to the disruption itself". In contrast, Fearn-Banks $(2007$, p. 8) define crisis in a more general way, including organizations and companies as well. She argues that "a crisis is a major occurrence with a potentially negative outcome affecting the organization, company, or industry, as well as its publics, products, services, or good name. A crisis can be a strike, terrorism, fire, a boycott, product tampering, product failure, or numerous other events."

But there is a major difference between an explosion resulting from a terrorist act and a boycott. A boycott may be seen as a crisis by the affected company, but doesn't result in loss of life but an explosion on an oil platform or an engine room of a ship can and does result in serious injuries and loss of property and life. So a crisis that is created by an event doesn't necessarily have to lead to extreme negative outcome(s). Extreme crises, on the other hand do, and are created by extreme events.

Hannah, Uhl-Bien, Avolio, and Cavarretta (2009) define an extreme event as "a discrete episode or occurrence that may result in an extensive and intolerable magnitude of physical, psychological, or material consequences to - or in close physical or psycho-social proximity toorganization members". They name the environment within which these extreme events take place as "extreme context", which they define as "an environment where one or more extreme events are occurring or are likely to occur". 
Clearly the context of an environment plays an important role in turning an event into a crisis or even an extreme crisis. Orasanu \& Lieberman (2010) consider 3 dimensions to characterise various extreme environments: 'ambient environment', 'social environment', and 'the nature of the task'.

Ambient extreme is defined as a hostile environment where life would be lost in absence of lifesustaining technologies. Space, Arctic, Antarctic and subsea environments are some of the examples of ambient extremes. Social extremes are environments where the social conditions can be inherently inhospitable such as prison, riot control, and war. Task extreme is a situation where the task at hand is dangerous, regardless of the environment. Bomb disposal, free-fall parachuting, or extreme sports can be examples of these extreme tasks. Using these three dimensions, they categorise extreme environments into four categories from least extreme to most extreme (Figure 2)

$\begin{array}{cccc}\text { Normal environment } & \begin{array}{c}\text { Extreme social } \\ \text { Extreme behavior }\end{array} & \begin{array}{c}\text { Extreme environment } \\ \text { extreme behavior }\end{array} & \begin{array}{c}\text { Isolated confined } \\ \text { Extreme environment }\end{array}\end{array}$

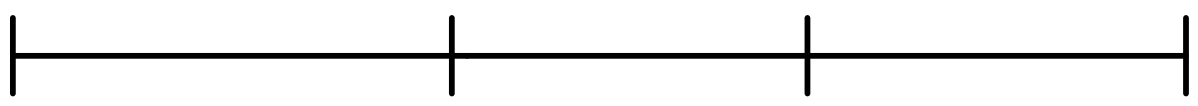

\begin{abstract}
Olympic sports
Rock climbing

Auto racing

Bunjee Jumping
\end{abstract}

(a)

\begin{abstract}
Military operations Hostage negotiations Human intelligence Peacekeeping ops
\end{abstract}

(b)

Coast Guard rescue
Acrobatic flying
Ocean racing
Mountain climbing

(c)
Space (ISS, lunar, Mars) Capsule simulation habitats Nuclear submariens Antarctica - overwintering

(d)

Figure 2. Categories of extreme environments from least (a) to most (d) extreme. (Source: Orasanu \& Lieberman, (2010, p. 4))

Dealing with extreme events in extreme context requires a special type of leadership. Normal decision making processes take time and may involve extensive examination of the available alternatives and their consequences; something that requires information, time and resources, all of which will most probably be in short supply. Hannah et al. (2009) have considered this problem and have produced a typology, outlining the problem areas (fig. 3).

They (Hannah et al., 2009) argue that time, the probability of an event happening, the magnitude of the consequences; the proximity and the form of the threat are constituent parts of the extreme context. They go on to argue for an adaptive leadership response. Ideally this response will reduce the level of extremity. Here we have elements such as time and complexity that tend to amplify or intensify the level of extremity which in turn can be reduced by using attenuators such as psychological, social and organizational resources.

Their typology unfortunately does not take into account the ambient or environmental conditions, which should be included as an intensifier. Nevertheless their typology as presented in figure 3 is still valid, especially with regard to the type of needed leadership response, which they define as:

\footnotetext{
"Adaptive and administrative processes of influencing others to understand and agree about what needs to be done and how to do it, and the process of facilitating individual and collective efforts to accomplish shared objectives and purpose under conditions where an extensive and intolerable magnitude of physical, psychological, or material consequences may exceed an organization's capacity to counter and occur to or in close physical, social, cultural, or psychological proximity to organization members." $(2009$, p. 913$)$
} 


\section{Sense-Giving Systems}

Making decisions in crisis situation is never easy. It is made even more difficult by the time constraint and the complexity of the situation (intensifiers). The decision maker has also to deal with a certain level of confusion that tends to exist immediately after the occurrences of an extreme event. The state of the systems, equipments and people may not be known. In these circumstances the first priority of a decision maker is to acquire a picture of what is going on and the state of available resources.

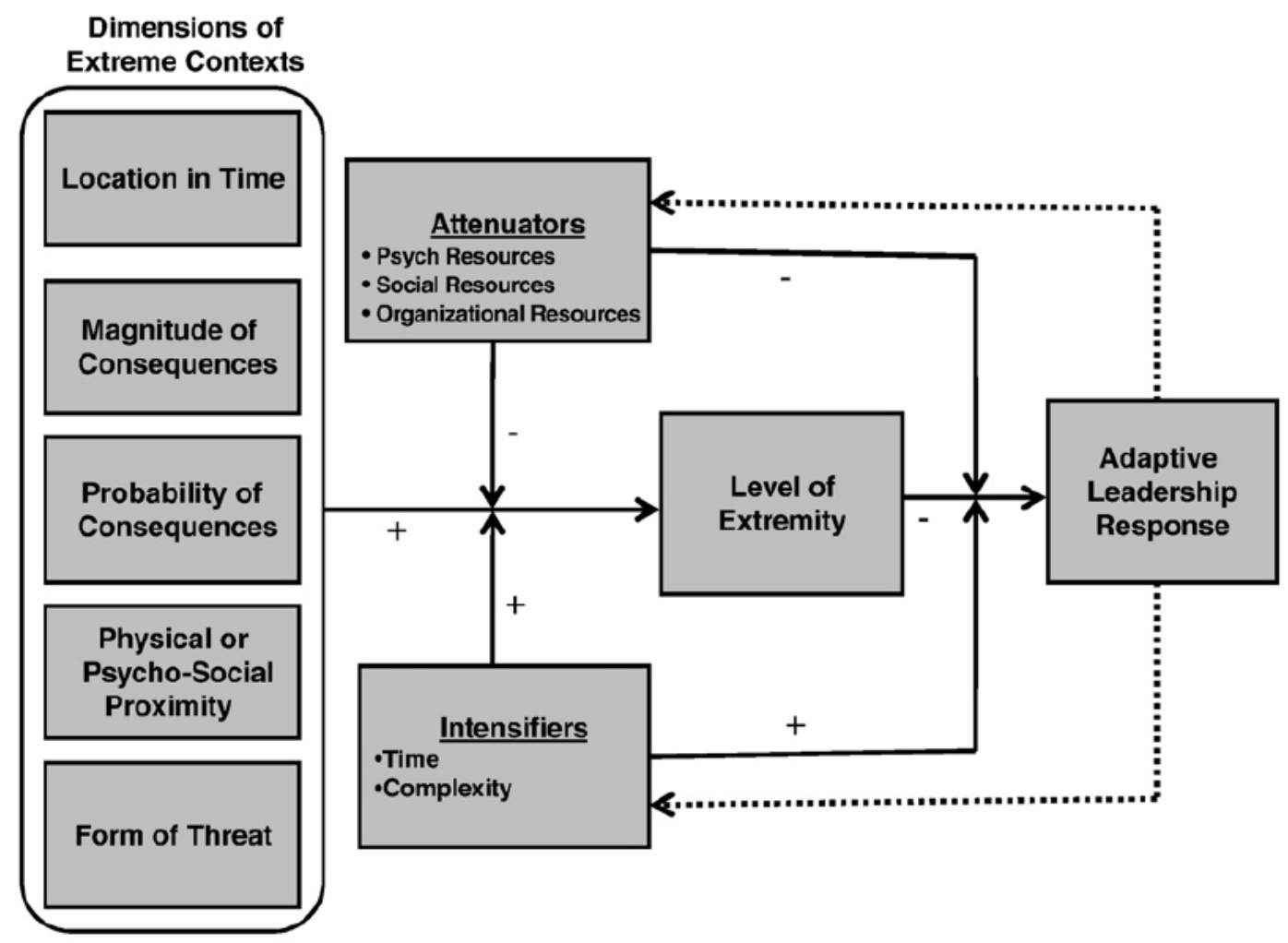

Figure 3. Typology of extreme context. Source Hannah et al. (2009, p. 899)

\section{Situation Awareness (SA)}

In extreme environments, many decisions are required across a fairly narrow space of time, and tasks are dependent on an ongoing, up-to-date analysis of the environment. Because the state of the environment is constantly changing, often in complex ways, a major portion of the decisionmaker's job becomes that of obtaining and maintaining a good understanding of the current situation.

A decision maker's situation awareness is the key feature dictating the success of the decision process in most real-world decision making. Decision makers in complex domains must do more than simply perceive the state of their environment in order to have good situation awareness. They must understand the integrated meaning of what they perceive in light of their goals. Situation awareness incorporates an operator's understanding of the situation as a whole, which forms the basis for decision making. The integrated picture of the current situation may be matched to prototypical situations in memory, each prototypical situation corresponding to a 'correct' action or decision.

SA of course is composed of two parts: situation and awareness. Pew (2000, p. 29) defines a situation as: 
"A set of environmental conditions and system states with which the participant is interacting that can be characterized uniquely by a set of information, knowledge and response options."

This definition of a situation can be further elaborated to encompass the following characteristics: current state of the system - including all relevant variables;

- predicted state in the "near" future;

- information and knowledge required in support of the team's current activities;

- activity phase;

- prioritized list of current goal(s);

- currently active goal, sub-goal, task;

- time;

- information and knowledge needed to support anticipated "near" future contexts.

The second part, or the awareness, is primarily a cognitive process resulting in awareness. Some definitions put a higher emphasis on this process than the other (situation). For example Endsley (1995, p. 36) defines SA as "the perception of the elements in the environment within a volume of time and space, the comprehension of their meaning, and the projection of their status in the near future."

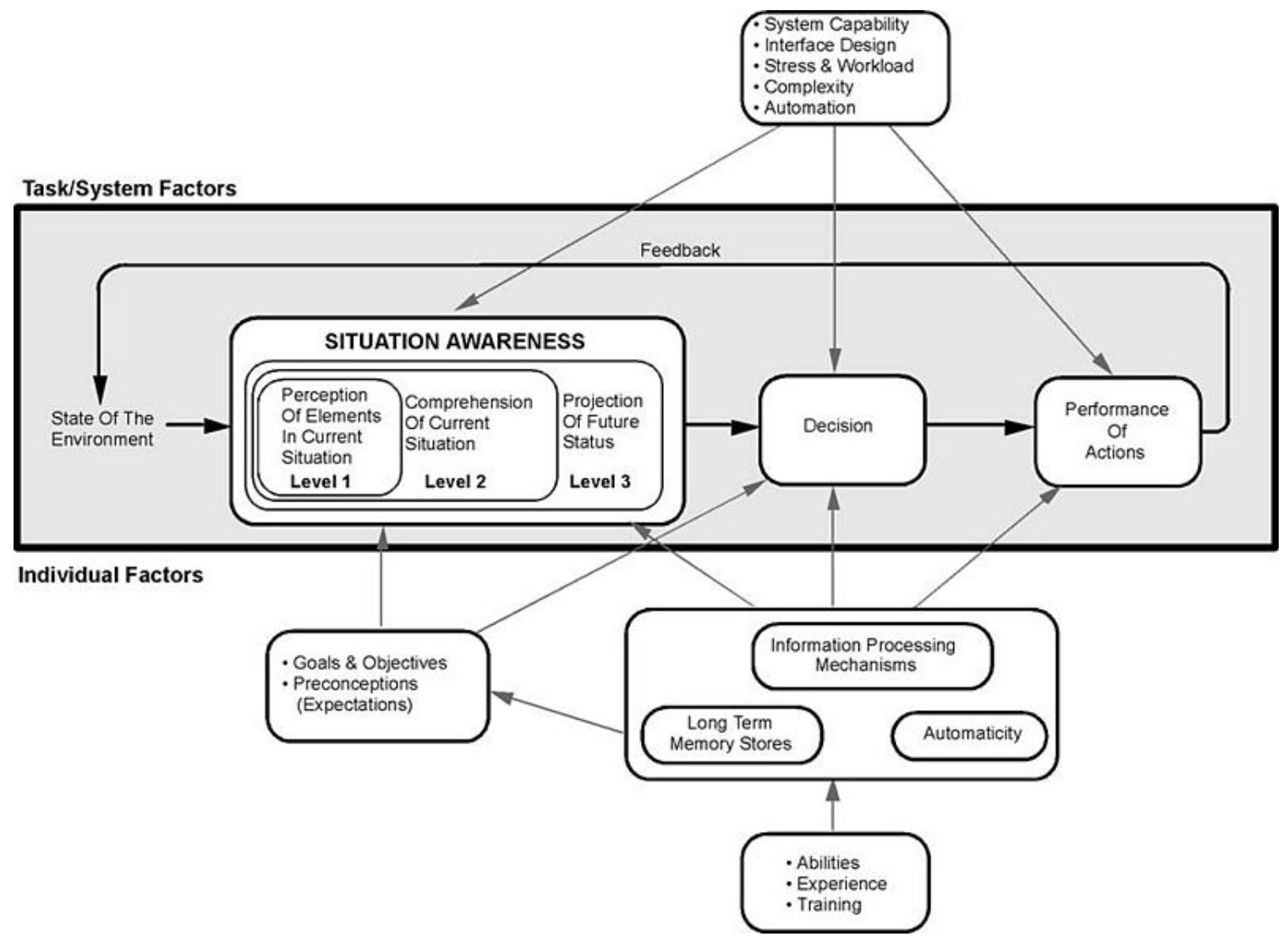

Figure 4.Endsley's model of situation awareness (SA). Source Endsley (1995, p. 35)

Endsley (1995) claims that SA is a state of knowledge that needs to be distinguished from the processes that are used to achieve that state. These processes should be referred to as situation assessment. In the context of figure 4, mental models help (or block) a person in the process of determining what information is important to attend to, as well as helping to form expectations. 


\section{Sense-Giving Systems}

Without a mental model it would be difficult to obtain satisfactory situation awareness. Processing novel cues in situations where good mental models don't exist, strains limited working memory and makes achieving SA much harder and more prone to error. Mental models provide default information (expected characteristics of elements) that help form higher levels of SA even when needed data is missing or incomplete. Mental models affect the way we handle decisions and actions under uncertainty.

According to Endsley and Garland (2000, p. 8), these mental models are formed by the available information. This information can be obtained from various sources such as:

- sensory information from the environment

- visual/auditory displays

- decision aids and support systems

- extra- and intra-team communication

- team member background knowledge and experience

These information sources will have different levels of reliability giving rise to different levels of confidence in various information sources. Furthermore, any model of information behaviour must indicate something about different stakeholder' information needs and sources. Information needs are primarily aimed at: 1) reducing uncertainty in decision making and 2) interpretation and sense-making in relation to the current situation. Hence, SA is derived from a combination of the environment, the system's displays and other people (team members) as integrated and interpreted by the individual.

SA is a vital component of the decision making process regardless the extremity of the environment within which the decisions are made. SA shapes the mental model of the decision maker and as such influences the perceived choice alternatives and their outcomes.

\section{Sense Giving}

As was mentioned earlier, decision makers facing an extreme event taking place in a complex domain must do more than simply perceive the state of their environment in order to have good situation awareness. They must understand the integrated meaning of what they perceive in a very limited time. This requires seeking or scanning the internal and external environment for information that can not only presents the status of the organization, personnel, systems, and available resources but also the cause and severity of the event; all of which should take place under sever time limitation. This situational awareness in organizational context is called 'sense making' and is influenced partly by other stakeholders' sense making of their own individual situation and perception of the event.

An event impacts individuals differently, depending on their state of mind, their psychological and physical proximity and the extent and form of the threat. When these individuals report their understanding of the event, they report their perception of the event which can be different from the reality, at least as perceived by others. They first try to make sense of their own situation (situational awareness) and understand the event and then try to transmit that information to others. This transmission of situational information is called sense giving.

Maon and Swaen (2009, p. 8) citing Bartunek et al. (1999), Gioia \& Chittipeddi (1991) and Rouleau (2005), define sense giving as "efforts to communicate thoughts about organizational events and features to others, to influence outcomes, and to increase support for its own perspective through suggestive or persuasive language as well as symbolic or emphatic actions".

In extreme events, a leader or a leadership group may be swarmed by information coming in from individuals whose sense giving may actually distort the reality of the situation and take away at- 
tention from vital issues. This distortion may occur at different levels of the organization; the lower the level, the higher the urgency for an immediate action. In an extreme event the physical or psychological proximity may act as a distortion factor in sense-making and sense-giving process.

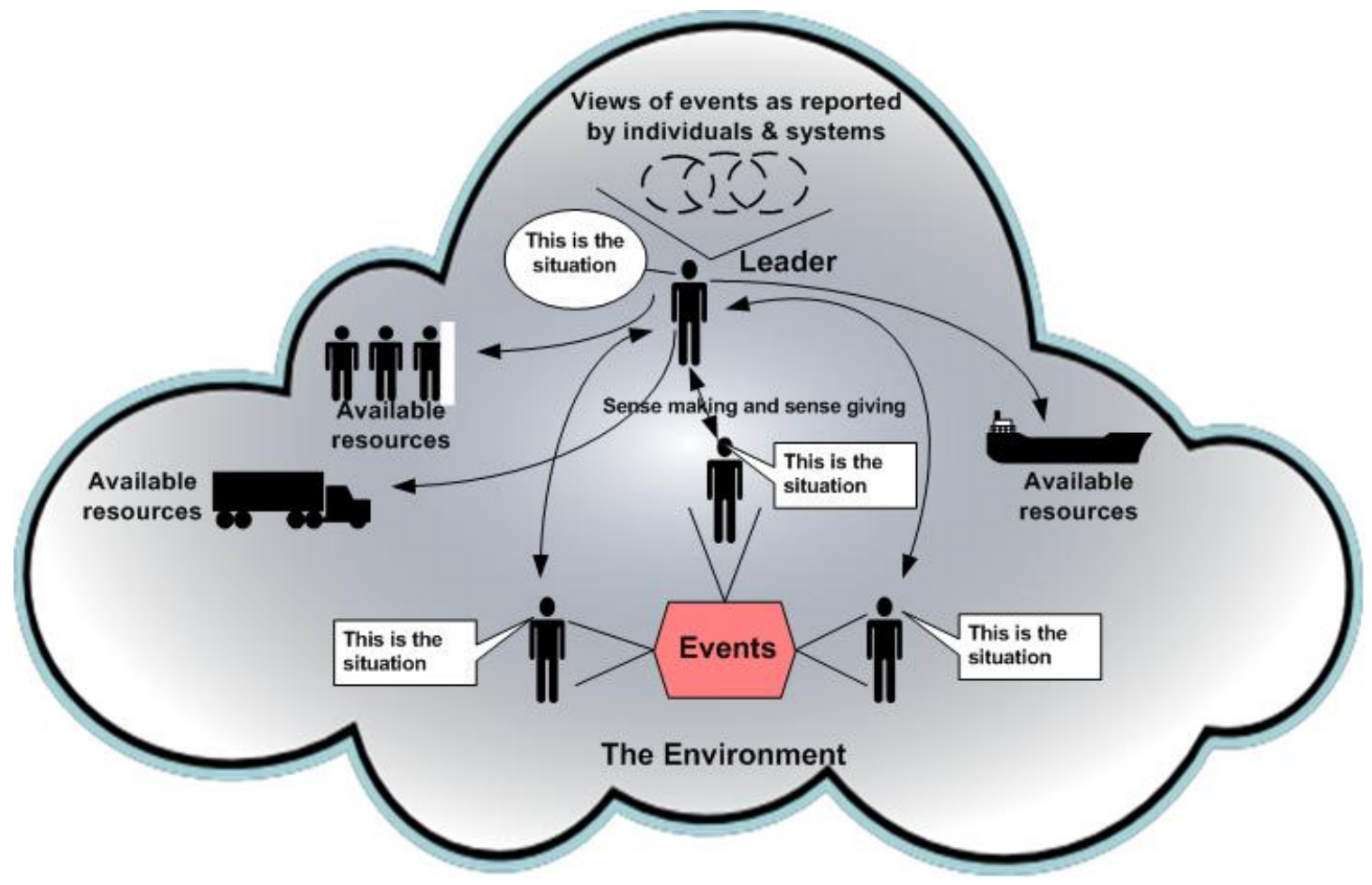

Figure 5. Sense making and sense giving

Figure 5 presents the sense making and sense giving processes involved in a crisis situation. The decision maker keeps receiving subjective reports from individuals based on their situational awareness. The decision maker has to continually mesh these reports and create an overall assessment of the situation, after which he/she has to inform (sense giving) the affected individuals and other actors (stakeholders) with his own assessment of the situation and decisions on courses of action to be taken. Here we must note that the decision maker's sense giving can and does change the situational awareness of the affected individuals.

For example, if a ship is struck by an iceberg and there is a gash on the side of the ship and water is coming through, the crew in the vicinity of the damage may see the situation as extremely dangerous and may even determine that immediate evacuation is the best response to the event. The captain and others on the bridge may see this as a bad situation but that sealing the affected area and sailing to the closes port may be the best response. Here the captain of the ship has to assess the situation and inform others in the affected area of the proper action to be taken. In these circumstances, the sense giving action is as important as the decision itself, for it can affect the psychological state of mind of those immediately affected by the event and hence their actions and performance. In addition, this sense-giving can also provides others with a broader picture of the event and hence help them to readjust their sense making process.

\section{Decision Making Modes in Extreme Environments}

Obtaining a better understanding of dynamic decision making process under extreme conditions will promote a better understanding of technology-mediated interaction between information sys- 


\section{Sense-Giving Systems}

tems and its users and between actors operating in dynamic and challenging environments in general (Fidel \& Pejtersen, 2004). In addition, it will better equip the decision-maker to determine the requirements that must be imposed on information systems support in dynamic and complex work environments (e.g. enterprise information systems, workflow management systems, decision support systems, web-based support systems and business intelligence tools). Bourgeois and Eisenhardt (1988) have shown that performance differences between organizations operating in dynamic and complex environments are related to how people decide and act (i.e. the decisionprocesses and subsequent execution of decisions). Moreover, decisions are influenced substantially by the patterns of real-time information flow and other modes of communication among the various organization units or members of a team (Herbert A. Simon et al., 1987). The main limitations of traditional decision-making theory and the developments based on it are its relative neglect of the limits of human (and computer) problem-solving capabilities in the face of real-world complexity.

According to Galbraith (1974) it is important to provide relevant information that enables decision-makers to make better decisions in the face of uncertainty; in particular, the greater the level of uncertainty in a task, the greater the amount of information that must be shared and processed among decision-makers. The degree of task uncertainty involves a combination of variables, and as this combination's complexity increases, there is an increasing need to provide relevant realtime information to decision-makers.

Decision making is often categorized into rational/analytical and naturalistic/intuitive decision making (Roy, Breton, \& Rousseau, 2007) . This distinction refers to two broad categories of decision-making modes that are not mutually exclusive. This implies that any given decision process in reality consists of analytical as well as intuitive elements.

Rational or analytical decision making prescribes the use of procedures, methods, and tools for identifying, clearly representing, and formally assessing important aspects of a decision. Thus, the analytical approach is a relatively slow, conscious, controlled and deliberate process mostly unsuited for the type of situations experienced in extreme environments. Naturalistic/intuitive decision making, on the other hand, refers to quick and relatively automatic decision processes. Each of these modes of decision making is used in specific circumstances, and the different characteristics of these two modes will prescribe different requirements with regards to information systems support. Each category has spawned several models, each of which is suitable for a particular environment. This branching of approaches is presented in figure 6 . 


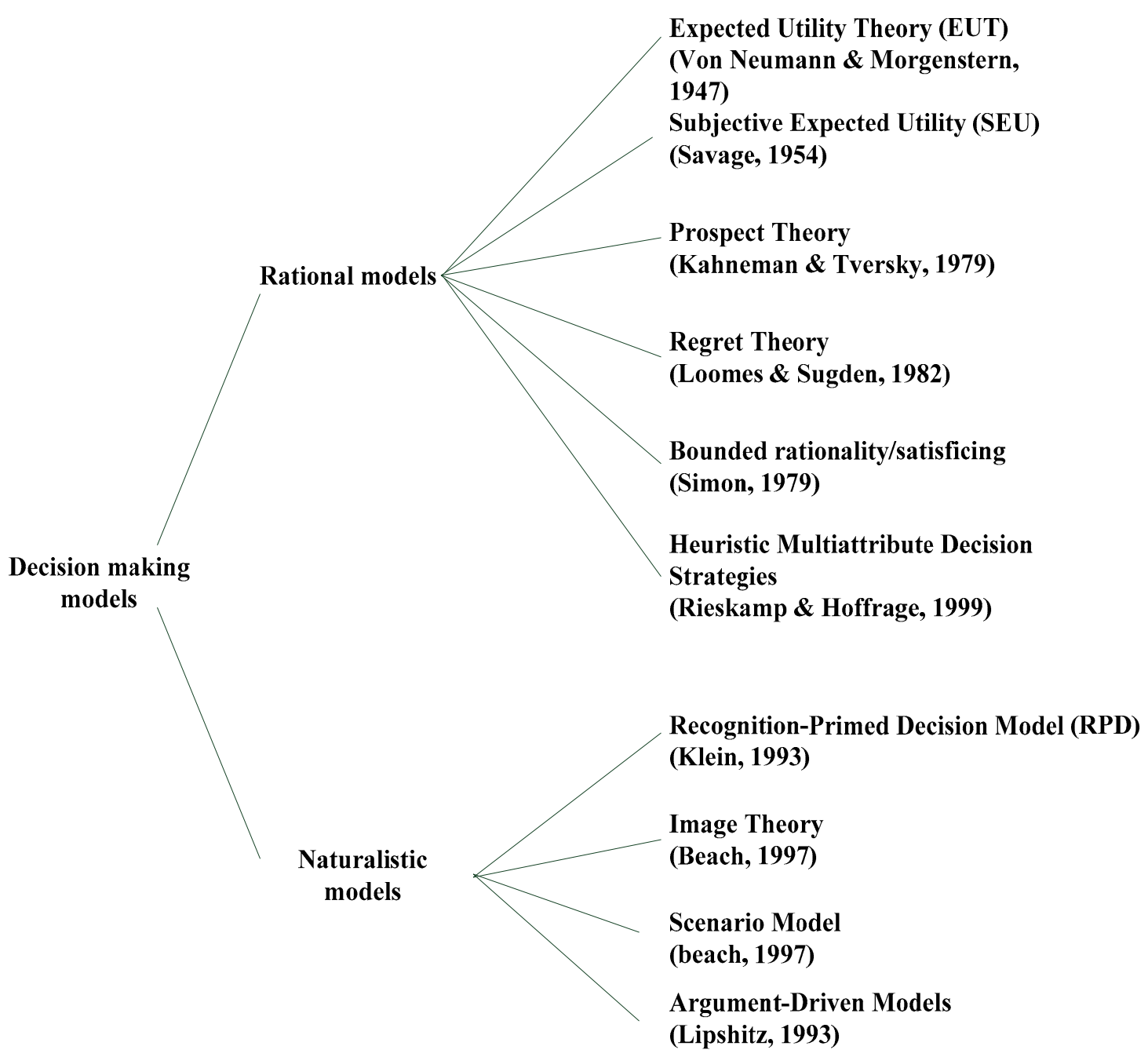

Figure 6. Decision making modes

Here we will not try to give an in-depth account of all decision-making models, but rather focus on the most important characteristics of the two main models: rational and naturalistic decision making models.

\section{Rational Decision Making}

The essential ingredients of classical decision-making are the assumption that the decision-maker is faced with several choice alternatives and their outcomes. To say that a person has made a decision implies that the decision-maker has made a judgment regarding what one ought to do in a certain situation after having deliberated on some alternative courses of action (Eilon, 1969; Ofstad, 1961) . Gorry and Scott Morton (1971) categorize decisions on a continuum from highly programmable to non-programmable decisions.

Decisions are programmable or structured to the extent that they are routine, repetitive, structured and are based on well-defined procedures. Such programmable decisions are regulated by rule or policy and the decision-maker has access to complete or near complete information. The techniques used during programmable decisions are related to habit (including knowledge and skills), well-defined routines and standard operating procedures. In addition, the organization's structure 


\section{Sense-Giving Systems}

and culture (i.e. the system of common mental models) and well-defined information channels, plays a crucial role in programmable decision making.

Non-programmable or unstructured decisions, on the other hand, are unique, non-recurring, unstructured and uncertain. These types of decisions require judgment, creative thinking and, in many cases, require a custom-made solution. Non-programmable decision-making is best suited for people who possess the qualities of judgment, intuition and creativity. A summary of the characteristics of different decision types are illustrated in figure 7.

$\begin{array}{lr}\text { Structured decisions } & \text { Semistructured decisions } \\ \begin{array}{l}\text { Established situation } \\ \text { Ordinary } \\ \text { Repetetive }\end{array} & \begin{array}{r}\text { Unstructured decisions } \\ \text { Issues understood } \\ \text { Knowledge readily available } \\ \text { Programmable }\end{array} \\ \text { Novel, unique } \\ \text { One-shot } \\ \text { Issues elusive } \\ \text { Knowledge difficult to get } \\ \text { Creative }\end{array}$

Figure 7. Continuum of decision types. Source: Holsapple \& Whinston (1996)

The classical normative economic theory assumes complete rationality during decision-making processes. The well-known model of the 'economic man' encompasses decision-making facing the complexities of the real world. Here, in order to maximize returns, the rationally best course of action is selected among all available possibilities. This is of course an unrealistic model. It has been shown that there is a substantial non-rational element in people's thinking and behaviour (Kahneman \& Tversky, 1979) along with practical limits to human rationality. The limits of human rationality are imposed by the complexity of the world, the incompleteness and inadequacy of human knowledge, the inconsistencies of individual preferences and belief, the conflicts of value among people and groups of people, and the inadequacy of the amount of information people can process/compute. The limits to rationality are not static but depend on the organizational context in which the decision-making process takes place. Hence, it is important to design the decision-making environment in such a way that a decision-maker can come as close as possible to make rational decisions.

Simon (1979) proposes a descriptive model where the decision-maker selects a course of action that is satisfactory or good enough. In this 'satisficing' process, the decision-makers are content with simplifications, taking into account only those few relevant factors that can cognitively be managed. Faced with the problem of bounded rationality, most human or organizational decisionmaking is thus concerned with the discovery and selection of satisfactory alternatives. Bounded rationality is the perception of one's reality that is restricted by the available information, their cognitive limitations, and the finite amount of time they have to make decisions.

Research in decision making under uncertainty have identified a number of ways in which the classical model of how decision alternatives are assessed in terms of their consequences falls short. According to March (1978), there are cognitive, political and organizational limits to rationality.

Cognitively, the level of attention or situational awareness as well as the limited mental capacity is the constraining factors. In addition, theories of choice have presupposed that a decisionmaker's future preferences are objective, stable, and known with satisfactory precision, making decisions unambiguous. In reality, people change their minds regarding what they want and they may even ignore their preferences and follow other recommendations or traditions.

In the case of collective decision making, there is also the problem of conflicting objectives and preferences representing the values of different members of a decision-making group. This is re- 
lated to political limits to rationality. March and Cyert (1963) assert that any kind of organization is in essence a political coalition with multiple and shifting goals. Here, negotiations regarding, for instance, company structure or organizational goals takes place within these coalitions. Hence, the focus of political decision models is that decision making occurs as a result of political bargains between key power brokers and interest groups.

Decision-making generally reflects the conflicts, major stakeholders, diverse interests and different levels of power in the organization, something that often results in high levels of confusion in the organization. The organizational limits to rationality is, in turn, determined by what March calls organized anarchies and states that organizations are not rational. Decision-making is largely accidental and is the product of a stream of solutions, problems and situations that are randomly associated. This mode of decision making was first described by Cohen, March and Olson in what they called the garbage can model of organizational choice (Cohen, March, \& Olsen, 1972) .

The notion of cognitive uncertainty (Michel, 2007) is a more recent elaboration of the problem of bounded rationality that, in essence, is related to cognitive and mental limits. Cognitive uncertainty is a subjectively perceived state of 'low prior confidence' concerning the precision or significance of one's own knowledge about a new situation. Persons who experience cognitive uncertainty recognize that they cannot effectively solve a problem because they are missing indispensable information, have conflicting information, cannot see cause-effect relationships, sense ambiguity about available courses of action and the potential of consequences, or are unable to distinguish between relevant and irrelevant information.

In line with the Carnegie School of decision making, organizations try to reduce cognitive uncertainty in order to reduce the cognitive load on employees. Information services supplied by different information system solutions provide a basis for the reduction of cognitive uncertainty and for informed decision-making at all levels of the organization. Hence, a primary purpose of information is to reduce uncertainty in a given situation. The role of information is a crucial point of difference between a more normative statistical approach to decision-making in situations characterized by risk (i.e. situations where probabilities may be assigned) and the satisficing approach for situations characterized by genuine uncertainty. In these situations, such probabilities cannot be estimated. In rational decision making, increases in information are usually assumed to reduce uncertainty both in estimates of probabilities and in the decision-maker's subjective belief in these estimates. In the satisficing approach, added information may - depending on the circumstances - either decrease or increase the subjective uncertainty of the decision-maker.

\section{Naturalistic Decision Making (NDM)}

The combination of ambiguity, dynamism and limited opportunities for information gathering is making the process of decision making a difficult task in most circumstances. In extreme, dynamic environments the importance of factors like time pressure, uncertainty, ill-defined goals, high personal stakes, and other complexities makes decision making in real-world settings an extremely challenging undertaking.

Since the 1980s, a considerable amount of research has been conducted on how people make decisions in real-world complex settings (G. Klein, Orasanu, Calderwood, \& Zsambok, n.d.; Todd, 2001; Zsambok \& Klein, 1997). This research has found significant differences from the idealized, rational model of decision making in which optimization across possible alternatives is featured. Instead, researchers in many complex domains find that people will act first to classify and understand a situation. This internal mental model of the situation generates the appropriate response from memory, followed by the selection of the proper action. Dreyfus (1982) emphasized the role of situational understanding in expert decision-making in real-world settings. According 


\section{Sense-Giving Systems}

to Dreyfus, experts use pattern-matching mechanisms and long-term memory structures to quickly understand a given situation. They then adopt the proper course of action corresponding to that particular type of situation. An important consequence of Dreyfus' observation is that these experts do not spend much time considering possible alternative courses of action. On the other hand, the majority of decision-maker's time and effort is spent in assessing and classifying the current situation. Hence, naturalistic decision-making (NDM) represents a very different perspective on how decision-making can be researched and understood than the more traditional models (Klein, 2008).

One of the most important features of naturalistic decision making is the explicit attempt to understand how people handle complex tasks and environments. According to Zsambok (1997), NDM can be defined as

"how experienced people working as individuals or groups in dynamic, uncertain, and often fast-paced environments, identify and assess their situation, make decisions, and take actions whose consequences are meaningful to them and to the larger organization in which they operate".

Thus, NDM can be said to be an individual's use of his or hers experience to reach a decision in a particular context of a work activity. According to Roy et al. (2007, p. 5), the contextual factors influencing decision-making are:

- Non-structured situations and problems;

- Uncertain and dynamic environments;

- Ill-defined, conflicting, or changing objectives;

- A decision-action-feedback cycle;

- Time pressure;

- Involvement of several individuals;

- Existence of organizational norms and objectives;

- Presence of high and potentially personal stakes.

One of the best known models of naturalistic decision making (NDM) is the Recognition-Primed Decision (RPD) model which was developed by Klein (2008) and colleagues (G. Klein, 1993; G.A. Klein, Calderwood, \& MacGregor, 1989a). According to RPD, the decision-maker does not elaborate and evaluate advantages and disadvantages of different alternative choices. Instead they use their experience and domain knowledge to size up a situation in order to find a solution or a course of action from first attempt. This model is thus suited for decision making in extreme and dynamic contexts characterized by uncertain, ambiguous and incomplete information in addition to strict time constraints. The RPD model consists of four components:

1. Recognition of current situation.

2. Understanding the situation in relation to the decision maker's goals and expectations as well as relevant cues.

3. Recall of relevant prototypical actions from previous experience.

4. Evaluation through mental simulation of potential consequences of each considered course of action.

The recognition of the current situation is based on the decision maker's familiarity with the situation compared to his/hers mental model and experience. Here, the use of situation-action decision rules matching refers to decisions with the basic structure of 'Do action A because it is appropriate for situation S' (Lipshitz, 1994). Through their studies, Klein et al. (1989b) have shown that decision makers typically make decisions by various forms of matching and not by concurrent choice. Thus, recognition of a situation activates an assessment process with no choice between a set of alternatives. If, however, the situation is unfamiliar, the decision-maker will seek informa- 
tion that can further clarify the situation. When the situation is familiar, the second component of the RPD comes into play. Here, the decision maker will try to understand the situation in relation to the decision maker's goals and expectations as well as relevant "cues". In general, a cue is an event of concern that may trigger more focused activity. When the situation is understood, the decision-maker will recall relevant prototypical actions according to the principle of the situationaction decision rule. The last part of the model is then evaluated through mental simulation. Here, the potential consequences of the considered course of action are evaluated independently of other alternatives. In effect, this is a mental visualization of how the situation could potentially develop if the considered action were realized.

Naturalistic decision making could, according to the RPD model, happen at three different levels of complexity (as illustrated in figure 8):

1. As a simple match

2. As a diagnosis of the situation, and

3. As an evaluation of the course of action

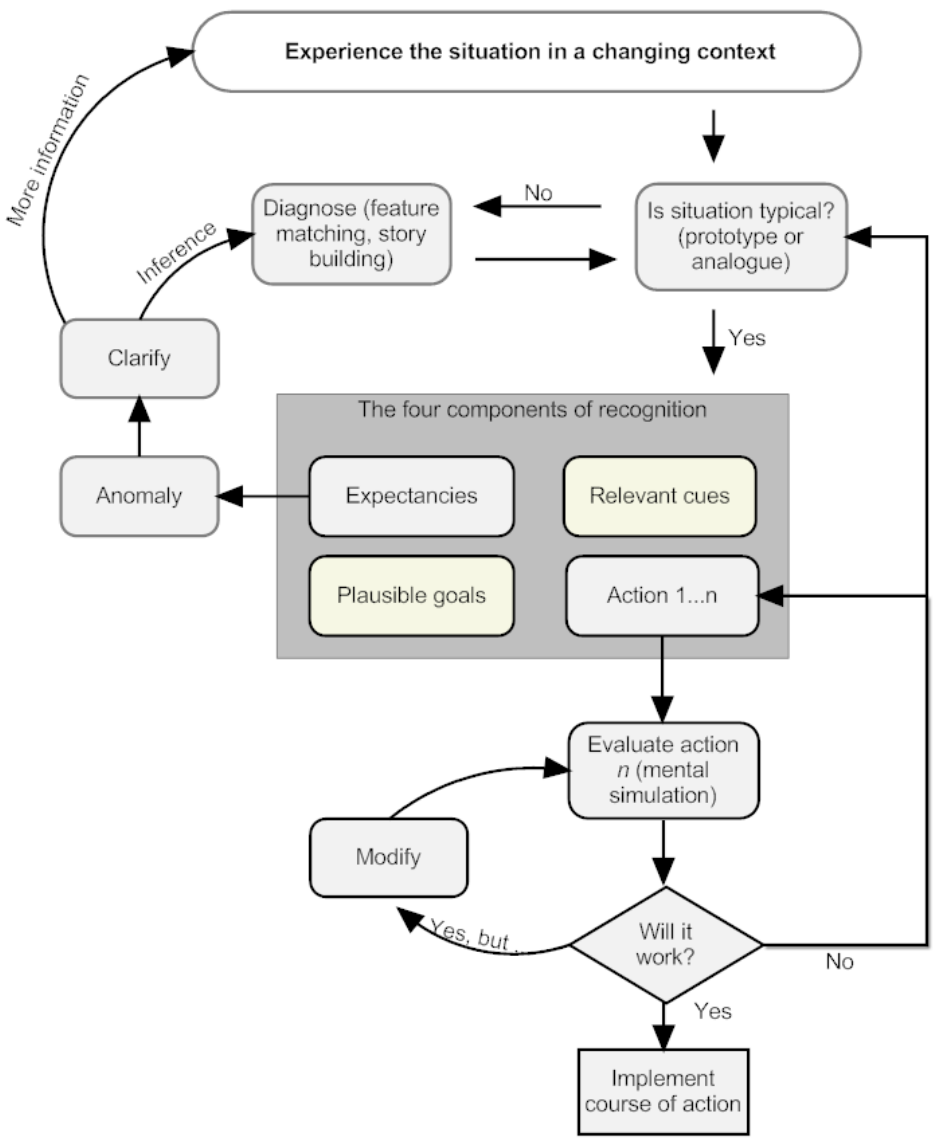

Figure 8. The recognition-primed decision model. Source Klein (1999)

Simple matching represents the straightforward case where a decision maker identifies or 'frames' a situation correctly. This means that the goals are obvious, all critical cues are attended to, expected future states are formed and a typical course of action is recognized. In situation diagnosis a decision maker will attempt to associate observed events with their causes in order to derive a viable explanation of the currently evolving situation. Diagnosis is important in naturalistic decision making because it is the main driver for determining the course of action. During the evaluation of possible courses of action the decision maker conducts a 'mental simulation' to de- 


\section{Sense-Giving Systems}

termine whether or not a given course of action will run into any difficulties, whether these difficulties can be managed, or whether a new course of action is needed?

Comparing Endsley's model of situation awareness (fig. 4) with the RPD model (fig.7), we see that there is a certain degree of overlap between these models. While the SA model visualizes the constituent parts of SA and the various factors that affect a decision maker's situation awareness (e.g. goals, experience/training, stress and workload, etc.), the RPD model gives a dynamic account of how decision making is played out in a real world situation. Here, a decision maker's situation awareness, i.e. the internal conceptualization of the situation, is a driving factor during the decision making process. The naturalistic model of decision making (e.g. RPD) emphasizes the role played by situation recognition in the selection of the appropriate action in a given situation. In contrast to rational models of problem-solving behaviour in which decision-making is based on the generation and evaluation of alternative actions, naturalistic decision making emphasizes the importance of recognizing a situation in terms of its 'closeness' to previously experienced situations and the execution of scripted response sequences that are associated with that situation.

\section{Decision Support Systems for Extreme Events}

Making decisions in response to an extreme event taking place in extreme environment requires both situational awareness and the ability to assess available alternatives and consequences, all of which depend on the availability of information on the environment, both external and internal, available resources and possible courses of actions. In these cases the primary focus has been on promoting Decision Support Systems (DSS) as an invaluable support to the decision makers.

Decision Support Systems are computer-based information systems that have been constructed to support individuals, groups and/or organizations in making decisions. As such these systems have evolved from two areas of research in organizational decision making and technology.

There are many definitions of what a DSS is and what it is supposed to do. One of the earliest definitions is provided by Gorry and Scott Morton (1971). They define a DSS as a system constructed for supporting decision making in 'unstructured' or 'semi-structured' decision situations. They emphasised that a DSS is not meant to replace or automate the decision making process or judgment of the decision maker, but rather act as an adjunct.

Later in 1980s, several people such as Keen (1980) and Bonczek, Holsapple and Whinston (1980) argued that structuredness concept (structured/unstructured) was only meaningful with respect to a particular decision maker or group of decision makers. For DSS definition to be meaningful, the system should include certain capabilities such as data analysis, extensible modelling, orientation towards future planning and used at irregular intervals.

Over-time the term DSS has been used liberally for any application that can be used in supporting decision making. This has been used by Turban, Sharda, \& Delen (2010) to define DSS as both an umbrella term used to describe any computerised system that support decision making and as a specific customised application built for unstructured or semi-structured problems.

DSS can be an extremely useful tool in decision making in the crisis situations or extreme events. It is particularly useful in extreme environments where the ambient environment (temperature, altitude, air, etc) plays an amplifying role in the extremity of an event. In extreme environments such as the ones found in the Arctic, automated information gathering on ambient environment, geographical locality of people, equipment and their status can be extremely useful to the decision makers; especially in sense making and sense giving processes. DSS can be used at all levels, from the operational level to the executive level, providing needed and relevant information to all. At the same time it is possible to allow individuals at different levels to access situational 
information on other actors and units, hence helping in unifying the situational awareness of the individuals and groups. Figure 9 shows this distributed socio-technical context of a DSS as a sense-giving system.

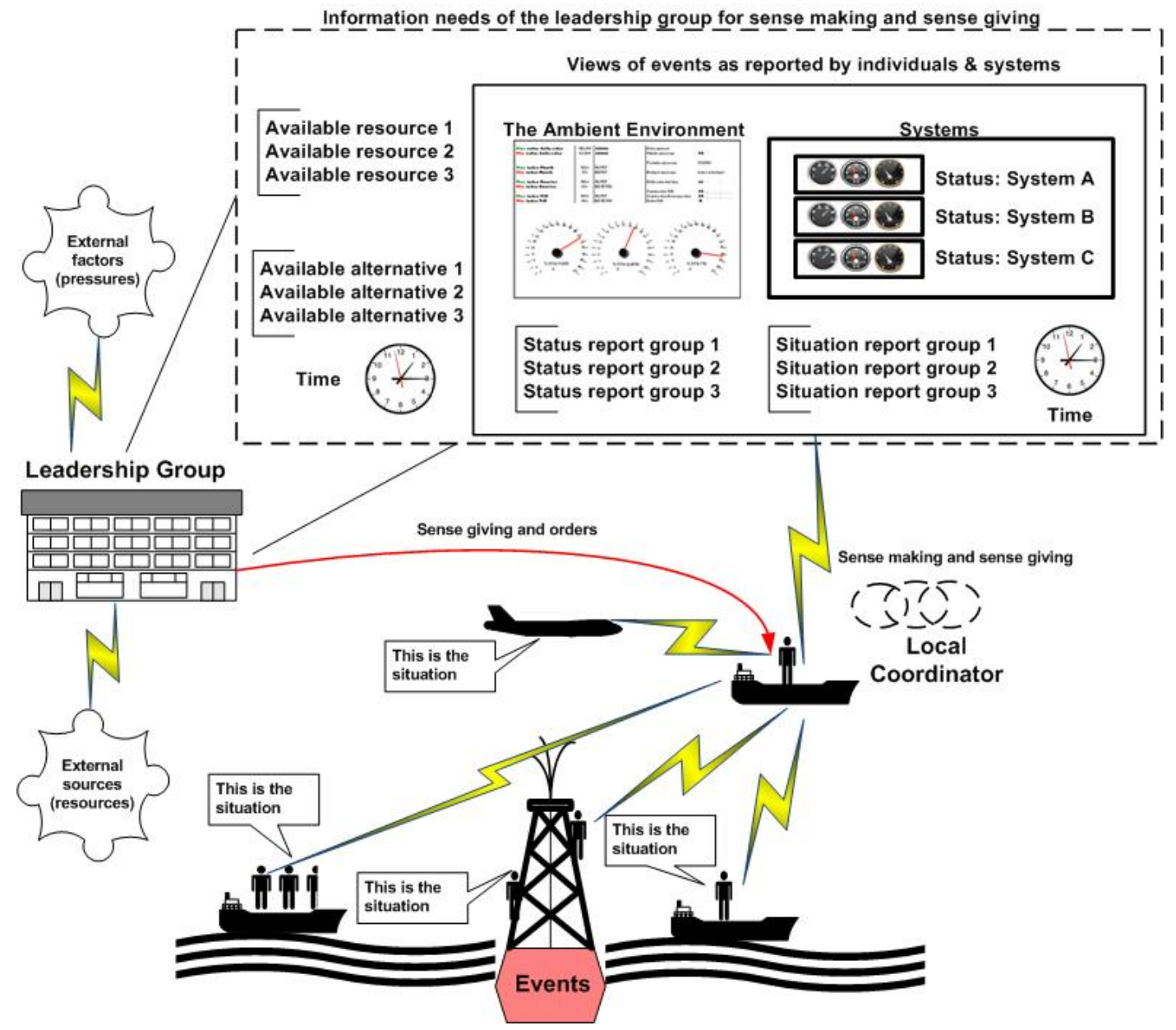

Figure 9. DSS as a sense giving system

In the remainder of this section we will outline some of the most prominent challenges facing the development of decision support systems in extreme environments: 1) understanding the context, 2) dynamic management of resources, 3) maintaining decision capabilities and 4) integration of heterogeneous information sources.

\section{Understanding Context}

According to Humphrey (1989), the analysis and specification of the requirements for a proposed system is perhaps the most important and difficult stage in any IT-related project. In an IT acquisition/development project, the consideration and analysis of the broader context, i.e. the sociotechnical system, is of utmost importance (Bostrom \& Heinen, 1977). According to Nuseibeh and Easterbrook (2000, p. 44) “... modelling and analysis cannot be performed adequately in isolation from the organizational and social context in which any new system will have to operate. This view emphasized the use of contextualized enquiry techniques, including ethno-methodology and participant observation". Furthermore, they emphasize the need for the development of new techniques for formally modelling and analyzing properties of the environment, as opposed to the behaviour of the software. Such techniques must take into account the need to deal with inconsistent, incomplete, and evolving models. These approaches will better support areas where Re- 


\section{Sense-Giving Systems}

quirement Engineering (RE) has been weak in the past, including the specification of the expectations that a software component has of its environment. Cheng and Atlee (2007) also calls for better techniques for integrating models of the environment, interface devices, and software components in requirements engineering, noting that human-behaviour modelling is still an open problem.

In any high-reliability organization (HRO), preparation for catastrophic events is done through contingency planning (Smith, 1990). The primary reason for contingency planning is to improve the quality of response in case of an emerging crisis. Experience shows that contingency planning can enhance the effectiveness, appropriateness and timeliness of response to emergencies. Contingency planning provides an opportunity to focus on operational issues and identify constraints prior to a crisis. We propose that an active contingency planning process must have a close relationship with the providers of technological solutions, e.g. decision support systems. This enables individuals, teams, and organizations to establish working relationships that can make a critical difference with regard to the quality of information systems solutions proposed. By working together in a contingency planning process, people develop a common understanding of common challenges, of each other's capacities and organizational requirements.

\section{Dynamic Management of Resources}

In general, extreme events have task structures that are categorized as "wicked" (Rittel \& Webber, 1973). Wicked problems are volatile and dynamic with a large amount of uncertainty, ambiguity and risk. Characteristics of wicked problems are:

- They represent ongoing problems with no inherent stopping rule;

- They change over time;

- They are solved when the problem no longer is of interest to stakeholders, when resources are exhausted or when some political agenda changes;

- There are many stakeholders with conflicting interests who repeatedly redefine what the problem is

- An ongoing consideration and reconsideration of causal factors;

- Multiple views between stakeholders regarding how to best approach and deal with the problem;

When operating in a complex and extreme environment, a general observation is that the potential complexity and dynamism inherent in these contexts calls for good management of available resources (i.e. personnel, equipment, time, etc.). Allocation (and reallocation) of scarce resources during a continuously changing situation is essential but poses a challenge since it often entails conflict, disagreement and negotiation between stakeholders involved (Turoff, White, \& Plotnick, 2011). Due to these factors, we will emphasize the need for an architecture that encompasses realtime resource allocation. According to Sommerville (2006), the components in a resource allocation system could include:

- A resource database that containing details of current resource allocation.

- A rule set describing the rules of resource allocation.

- A resource management component that enables the addition, editing and deletion of resources from the resource database.

- A resource allocation component that dynamically updates the resource database. when allocation and reallocation events unfold during the crisis. 


\section{Maintaining Decision Capabilities}

Another, but closely related, aspect of managing events in extreme environments is the need for maintaining robust decision capabilities as events unfold. As previously mentioned, a robust decision capability is dependent on a satisfactory understanding of what is going on in the environment, i.e. good situation awareness. According to Endsley's model of SA (Endsley, 1995), the decision capabilities directly influences the quality of the actions carried out as a response to some critical incident.

The cognitive and psychological aspects of decision-making affects the dynamics encountered in human-system interaction and the way these systems are used. This is a question about the nature of decision-making in contexts constrained by time factors, task complexity and rapid change (e.g. in critical operations in extreme environments). In these environments, the interaction for which the systems were originally made for can no longer be characterized by a simple relationship. In these situations the relationship changes to include semi- or ill-structured problems involving many attributes, objectives and goals. Consequently that operators shape the available tools based on their constraints and task demands.

When designing systems that acts like cognitive aids that maintain decision capability as events unfold, a thorough understanding of the interrelationship between operator's work load, stress level, mental model, information needs and decision making strategies is needed.

\section{Integration of Heterogeneous Information Sources}

The reality of operations in extreme environments is one consisting of a number of partially connected IT-systems (i.e. "systems of systems") where the efficient and effective integration of these diverse information sources represents a major challenge. Systems should be able to support the management of interdependencies or chains of inter-dependencies among elements in the socio-technical system and the various cues (events) occurring in the environment. Information integration or information fusion (Bossé, Roy, \& Wark, 2007) is the merging of information from disparate sources with differing conceptual, contextual and typographical representations. Problems regarding systems integration arise from mismatches in the relationship between information channels and seemingly discrete events that lead to sub-optimal decision making. Early approaches to systems integration tended towards a juxtaposition of systems' information flows within a common system or display. Here, integration is built around the technical aspects of the systems. True systems integration focuses on the seamless mesh of data fusion, data filtering leading to a managed information flow that entails information-rich situation awareness for optimal decision-making. Here integration is built around users' needs, the task environment and system's characteristics.

\section{Conclusion}

Extreme events are not something that can be planned for, especially with a view of constructing automated or semi-automated decision making systems. One can envision scenarios and plan for those, but as the events in Japan (the massive earthquake and subsequent tsunami and the nuclear crisis) or in the Gulf of Mexico (explosion on the Deepwater Horizon drilling platform) have shown even scenarios cannot cover all eventualities.

To deal with a crisis, one has to first make sense of the situation, i.e., what is happening and then assess the situation with regard to available resources and possible alternatives and their consequences. In extreme crisis, the magnitude of the event and its consequences are such that one experiences a time compression, where the response has to be immediate. 


\section{Sense-Giving Systems}

Extreme events taking place in extreme environments tend to, not only amplify this time compression, but also increase the response time. This can be caused because of for example, extreme ambient temperature, long distances involved, deep under water, etc.

In these situations, general contingency planning and allocation of resources for those contingencies can be extremely helpful, but not the solution.

In this paper we have argued for a view of decision-support technology as essentially a sensegiving aid to the formation and upholding of situation awareness during crisis in extreme environments. We have also discussed the differences between traditional notions of decision-making and naturalistic decision making, emphasizing the effect these differences will have on how we conceptualize decision support technologies. We have presented four major challenges to the development of efficient and effective decision support technologies for extreme environments and events:

1) Understanding of context.

2) Dynamic management of resources.

3) Maintaining decision capabilities and,

4) Transparent and reliable integration of heterogeneous information sources.

As a next step in our continuing research in sense-giving support systems for extreme events in extreme environments, we will concentrate our work on the problems associated with maintaining a high level of decision capability throughout a crisis. Here, we intend to perform an in-depth analysis of decision-making practices employed by experts working in various high-reliability organizations associated with oil-related operations in the arctic (land-based operations, supply vessel operations, drilling, etc.).

\section{References}

Aftabuzzaman, M., \& Mazloumi, E. (2011). Achieving sustainable urban transport mobility in post peak oil era. Transport Policy.

Aleklett, K., \& Campbell, C. J. (2003). The peak and decline of world oil and gas production. Minerals and Energy Raw Materials Report, 18, 5-20.

Bartunek, J., Krim, R., Necochea, R., \& Humphries, M. (1999). Sensemaking, sensegiving, and leadership in strategic organizational development. Advances in Qualitative Organizational Research, 2, 37-71.

Bentley, R. W. (2002). Global oil \& gas depletion: an overview. Energy Policy, 30(3), 189-205.

Bonczek, R. H., Holsapple, C. W., \& Whinston, A. B. (1980). The evolving roles of models in decision support systems. Decision Sciences, 11(2), 337-356.

Bossé, É., Roy, J., \& Wark, S. (2007). Concepts, models, and tools for information fusion. Artech House.

Bostrom, R. P., \& Heinen, J. S. (1977). MIS problems and failures: a socio-technical perspective. Part I: The causes. MIS Quarterly, 17-32.

Bourgeois, L. J., I., \& Eisenhardt, K. M. (1988). Strategic decision processes in high velocity environments: Four cases in the microcomputer industry. Management Science, 34(7), 816-835.

BP Statistical Review of World Energy June 2010. (2010). (pp. 1-50). British Petroleum. Retrieved from http://www.bp.com/liveassets/bp_internet/globalbp/globalbp_uk_english/reports and publications/stat istical_energy_review_2008/STAGING/local_assets/2010_downloads/statistical_review_of_world_energ y_full_report 2010.pdf

Cheng, B. H. C., \& Atlee, J. M. (2007). Research directions in requirements engineering. 2007 Future of Software Engineering (pp. 285-303). 
China oil demand is "astonishing." (2010, March 12).BBC. Retrieved from http://news.bbc.co.uk/2/hi/business/8563985.stm

Cohen, M., March, J., \& Olsen, J. (1972). A garbage can model of organizational choice. Administrative Science Quarterly, 17(1), 1-25.

Cyert, R. M., \& March, J. G. (1963). A behavioural theory of the firm. Englewood Cliffs, NJ: Prentice-Hall.

Dreyfus, S. E. (1982). Formal models vs human situational understanding: Inherent limitations on the modelling of business expertise. Information Technology \& People, 1(2/3), 133-165.

Eilon, S. (1969). What is a decision? Management Science, 16(4), B172-B189.

Endsley, M. R. (1995). Toward a theory of situation awareness in dynamic systems. Human Factors: The Journal of the Human Factors and Ergonomics Society.

Endsley, M. R., \& Garland, D. J. (2000). Situation awareness: Analysis and measurement. Routledge.

Fearn-Banks, K. (2007). Crisis communications: A casebook approach. Routledge.

Fidel, R., \& Pejtersen, A. M. (2004). From information behaviour research to the design of information systems: The Cognitive Work Analysis framework. Information Research, 10(1), 10-1.

Galbraith, J. R. (1974). Organization design: An information processing view. Interfaces, 4(3), $28-36$.

Gautier, D. (2011). US Geological Survey Circum-Arctic Resource Appraisal. OTC Arctic Technology Conference.

Gautier, D. L., Bird, K. J., Charpentier, R. R., Grantz, A., Houseknecht, D. W., Klett, T. R., Moore, T. E., et al. (2009). Assessment of undiscovered oil and gas in the Arctic. Science, 324(5931), 1175-1179. doi:10.1126/science. 1169467

Gioia, D. A., \& Chittipeddi, K. (1991). Sensemaking and sensegiving in strategic change initiation. Strategic Management Journal, 12(6), 433-448.

Gorry, G. A., \& Scott Morton, M. S. (1971). A framework for management information systems. Sloan Management Review, 13(1), 55-70.

Hannah, S. T., Uhl-Bien, M., Avolio, B. J., \& Cavarretta, F. L. (2009). A framework for examining leadership in extreme contexts. The Leadership Quarterly, 20(6), 897-919.

Holsapple, Clyde W., \& Whinston, A. B. (1996). Decision support systems: A knowledge-based approach (10th ed.). Course Technology Inc.

Humphrey, W. S. (1989). Managing the software process (1st ed.). Addison Wesley.

James, R. K. (2008). Crisis intervention strategies. Cengage Learning.

Kahneman, D., \& Tversky, A. (1979). Procpect theory: An analysis of decision under risk. Econometrica, 47(2), 263-291.

Keen, P. G. W. (1980). Adaptive design for decision support systems. ACM SIGOA Newsletter, 1(4-5), 1525.

Kerr, R. A. (2011). Peak oil production may already be here. Science, 331(6024), $1510-1511$. doi:10.1126/science.331.6024.1510

Klein, G. (1993). A recognition-primed decision (RPD) model of rapid decision making. Decision making in action: Models and methods. (pp. 138-147). Norwood, NJ: Ablex Publishing Co.

Klein, G. (1999). Sources of power: How people make decisions. The MIT Press.

Klein, G. (2008). Naturalistic decision making. Human Factors, 50(3), 456-460.

Klein, G., Orasanu, J., Calderwood, R., \& Zsambok, C. E. (n.d.). Decision making in action: models and methods. Norwood, NJ: Ablex Publishing Co. 


\section{Sense-Giving Systems}

Klein, G. A., Calderwood, R., \& MacGregor, D. (1989a). Critical decision method for eliciting knowledge. IEEE Transactions on Systems, Man, and Cybernetics, 19, 462-472. doi:10.1109/21.31053

Lipshitz, R. (1994). Decision making in three modes. Journal for the Theory of Social Behaviour, 24(1), 47-65. doi:10.1111/j.1468-5914.1994.tb00246.x

Maon, F., \& Swaen, V. (2009). Shaping the processual view of CSR: A multipartite sensemakingsensegiving conceptualization.

March, J. G. (1978). Bounded rationality, ambiguity, and the engineering of choice. The Bell Journal of Economics, 9(2), 587-608.

Mejlænder-Larsen, M. (2011, January 11). Operating ships in the Arctic: The arguments for a Polar Class and new IMO Polar Code. Powerpoint Presentation presented at the Workshop - Offshore service vessel performance and vessel management in arctic oil and gas expeditions, University of Tromsø.

Michel, A. A. (2007). A distributed cognition perspective on newcomers' change processes: The management of cognitive uncertainty in two investment banks. Administrative Science Quarterly, 52(4), 507 557. doi:10.2189/asqu.52.4.507

Mikelborg, Ø. (2011, January 11). Planning the Arctic expedition. Powerpoint Presentation presented at the Workshop - Offshore service vessel performance and vessel management in arctic oil and gas expeditions, University of Tromsø.

Nielsen, L. (2011, January 11). Offshore service vessel performance and vessel management in Arctic oil and gas expeditions. Powerpoint Presentation presented at the Workshop - Offshore service vessel performance and vessel management in arctic oil and gas expeditions, University of Tromsø.

Nuseibeh, B., \& Easterbrook, S. (2000). Requirements engineering: A roadmap. Proceedings of the Conference on the Future of Software Engineering (pp. 35-46).

Ofstad, H. (1961). An inquiry into the freedom of decision. Allen and Unwin.

Orasanu, J., \& Lieberman, P. (2010). NMD Issues in extreme environments. Informed by Knowledge: Expert Performance in Complex Situations (pp. 3-21). Routledge.

Pew, R. W. (2000). The state of situation awareness measurement: Heading toward the next century. Situation awareness analysis and measurement, 33-47.

Pidwirny, M. (2006). Introduction to the Oceans. www.physicalgeography.net. Retrieved April 5, 2011, from http://www.physicalgeography.net/fundamentals/8o.html

Rittel, H. W. J., \& Webber, M. M. (1973). Dilemmas in a general theory of planning. Policy Sciences, 4(2), $155-169$.

Rouleau, L. (2005). Micro-practices of strategic sensemaking and sensegiving: How middle managers interpret and sell change every day. Journal of Management Studies, 42(7), 1413-1441.

Roy, J., Breton, R., \& Rousseau, R. (2007). Decision-making models. Concepts, Models and Tools for Information Fusion (p. 392). Artech House Publishers.

Simon, H. A. (1979). Rational decision making in business organizations. The American Economic Review, 69(4), 493-513.

Simon, Herbert A., Dantzig, G. B., Hogarth, R., Plott, C. R., Raiffa, H., Schelling, T. C., Shepsle, K. A., et al. (1987). Decision making and problem solving. Interfaces, 17(5), 11-35.

Skrebowski, C. (2003). Global oil and gas depletion. Petroleum Review, 57(675), 32-35.

Smith, D. (1990). Beyond contingency planning: Towards a model of crisis management. Organization \& Environment, 4(4), 263-275.

Sommerville, I. (2006). Software engineering: Update (8th ed.). Addison Wesley.

Todd, P. M. (2001). Putting naturalistic decision making into the adaptive toolbox. Journal of Behavioral Decision Making, 14(5), 381-383. doi:10.1002/bdm.396 
Turban, E., Sharda, R., \& Delen, D. (2010). Decision support and business intelligence systems (9th ed.). Pearson Education.

Turoff, M., White, C., \& Plotnick, L. (2011). Dynamic emergency response management for large scale decision making in extreme hazardous events. Supporting Real Time Decision-Making, 181-202.

Zsambok, C. E., \& Klein, G. A. (1997). Naturalistic decision making. Routledge.

\section{Biographies}

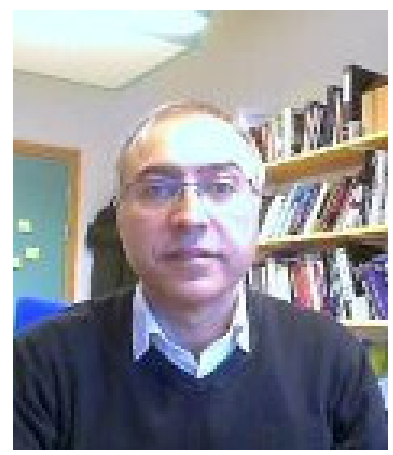

Abbas Strommen-Bakhtiar is an associate professor at the Centre for Enterprise Architecture and Information Systems, Graduate School of Business, University of Nordland. He has two BSc in Aerospace Engineering Technology and Computer Science, two MSc in Information Technology and Computer Integrated Manufacturing and a $\mathrm{PhD}$ in Strategic management. His main interests are in the areas of Management Information Systems and Strategic Management (including technology and innovation). He is currently working on several projects such as E-commerce, open source educational framework for Virtual University, the application and use of decision support systems in extreme environments. He also works as independent consultant.

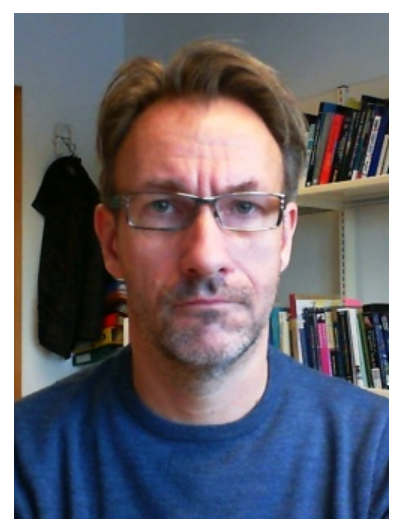

Eystein Mathisen is an assistant professor at Bodø Graduate School of Business. He has been teaching and doing research within computer science and information systems. His research interests are: decision making, decision support systems and ICT in healthcare. In addition he has some years experience from the IT-industry, developing computer systems for the telecommunications industry. 